\title{
LA DINÁMICA ENTRE LA BÚSQUEDA DE LA VERDAD Y LAS CONVENCIONES PROBATORIAS EN EL PROCESO PENAL
}

\author{
The dynamics between the search of the truth and the probative \\ conventions in the criminal process
}

Martina Cociña Cholaky*

\begin{abstract}
Resumen: El presente trabajo tiene por objeto aportar al estudio de la averiguación de la verdad como una de las finalidades esenciales del proceso penal. Para lograr aquello se analiza la relación existente entre la verdad y las convenciones probatorias; en particular la problemática que genera la incorporación de esta nueva herramienta en lo punitivo, al sustituir la constatación fáctica de lo aseverado, por lo que los intervinientes convienen como real; ahora lo real no se verifica, sino que se construye. Por tanto, el propósito de este artículo es denunciar la tensión que se produce entre el fin de la búsqueda de la verdad y la aceptación de una convención probatoria como mecanismo para establecer qué ha de entenderse como verdad a efectos probatorios.
\end{abstract}

Palabras clave: verdad - convenciones probatorias - proceso penal - prueba racionalidad.

Abstract: This paper seeks to contribute to the study of the search of the truth as one of the essential goals of the criminal process. In order to achieve that, it examines the relation between the truth and probative conventions; and particularly the problematic generated by the incorporation of this new tool in the punitive process by substituting the factual verification of what the parties has been said in the process, where they agreement of what reality is; now the "reality" it is not verifiable, but rather it is a construction. Therefore, the purpose of this paper is to denounce the tension between the goal of searching the truth and the acceptance of a probative convention as a mechanism to establish what has to be understood as truth for probative process.

Keywords: truth - probative conventions - criminal process - proof - rationality.

\section{Introducción}

El presente artículo, consciente de que la cuestión de la verdad es seguramente el problema central y a la vez el más difícil de la teoría del proceso penal, se abocará al análisis de la averiguación de la verdad, circunscribiéndolo específicamente a la relación que juega con las convenciones probatorias. Se opta por el examen de las convenciones probatorias y no por el estudio de otra institución o procedimiento,

*Licenciada en Ciencias Sociales y Jurídicas de la Universidad de Chile, Abogada de la División de Investigaciones de la Fiscalía Nacional Económica. Correo electrónico: mcocina@fne.gob.cl.

Este artículo fue recibido el 31 de octubre de 2012, siendo aprobada su publicación con fecha 8 de mayo de 2013. 
Cociña - La dinámica entre la búsqueda de la verdad y las convenciones probatorias...

como lo serían, por ejemplo, el efecto de las sentencias penales en lo civil, la exclusión de la prueba ilícita o el procedimiento abreviado, ya que las convenciones probatorias constituyen una nueva herramienta del proceso penal, que no ha sido estudiada con acuciosidad, a diferencia de otros mecanismos que presentan una dinámica similar con la verdad.

Para lograr lo anterior, en primer lugar, se examinará a grandes rasgos la problemática de la verdad en el ámbito punitivo; y, luego, cómo se concilia esta con las convenciones probatorias.

\section{La averiguación de la verdad en el proceso penal}

La verdad debe ser una de las temáticas más debatidas a lo largo de la historia, no solamente en el ámbito jurídico, sino también en la esfera filosófica, política y social. Concretamente la pregunta por la verdad es una problemática epistemológica en sentido amplio, es decir, suponiendo que existe una realidad externa y objetiva, consiste en la relación entre la realidad y el conocimiento relativo a esta.

De este modo la interrogante por la verdad se vincula a la filosofía política en la medida que remite indirectamente a las discusiones sobre el ejercicio del poder y sobre las condiciones de un orden social justo. El problema de la verdad es una cuestión política, que implica hacerse cargo de cómo se comprende la comunidad de la que se es parte; ello en la medida que toda sociedad presupone una manera de ejercitar el poder que la concreta y la respalda. De ahí que Carlos Peña sostiene que "el problema de las relaciones entre la verdad y la política es uno de los más recurrentes de la filosofía. Quizá se deba al hecho de que el trato cotidiano con la pluralidad, que es propio de la política, se hace aparentemente más dificultoso si la verdad se inmiscuye. Si entre todas las posiciones en disputa hay alguna que puede poner la verdad de su lado derrotando definitivamente a las demás ¿cómo se justifica la mantención del diálogo y de la diversidad? Algunos autores piensan que esa dificultad obliga a aventar la verdad del espacio de la política, mientras otros creen que asegurar la presencia de la verdad es la única forma de que la política no acabe estropeándolo todo".

Sobre el particular, considero que mientras en la esfera política actúen pretensiones de validez, y no meras predilecciones, la verdad tiene un papel no menor que cumplir. A su vez, en la construcción de toda concepción de verdad se reconoce una dinámica de poder subyacente, pues "por detrás de todo saber o conocimiento lo que está en juego es una lucha de poder. El poder político no está ausente del saber, por el contrario, está tramado con este". ${ }^{2}$ De esta manera se

\footnotetext{
${ }^{1}$ Peña, Carlos: "Habermas y el problema de la verdad", en Cuadernos de Filosofía del Derecho, Doxa, 32 (2009), p. 586.

${ }^{2}$ Foucault, Michel: La verdad y las formas jurídicas, 2a ed. Barcelona, Gedisa, 2003, p. 8.
} 
interrelacionan no solo la verdad y el régimen político, sino también el orden social imperante, pues el poder constituye una realidad propia de la dinámica asociativa, que es inherente a la idea de sociedad. En consecuencia, y tal como afirma Foucault, la verdad "tiene aquí efectos reglamentados de poder. Cada sociedad tiene su régimen de verdad, su política general de la verdad: es decir, los tipos de discursos que ella acoge y hace funcionar como verdaderos; los mecanismos y las instancias que permiten distinguir los enunciados verdaderos de los falsos, la manera de sancionar unos y otros; las técnicas y los procedimientos que son valorizados para la obtención de la verdad; el estatuto de aquellos encargados de decir qué es la que funciona como verdadero". ${ }^{3}$

Para alcanzar la verdad se estableció un instrumento civilizado, sustitutivo de la guerra, como lo es el proceso. Este último no está exento de la lógica de poder, pues al igual que el Derecho no es neutral, sino más bien responde a intereses políticos que se adecuan a un cierto tipo de sociedad. Bajo esta perspectiva, el proceso, el conocimiento y el poder se encuentran interrelacionados entre sí, y en esta tríada, la búsqueda de la verdad se estatuye como la constante a seguir, en tanto dota de racionalidad a la respuesta jurisdiccional, en particular, y a la administración de justicia, en general.

En este contexto, el derecho procesal se configura como el mecanismo que concreta la política substantiva. Por consiguiente, fijar determinados requisitos, etapas, procedimientos, plazos, responde a la ideología imperante. Esto en la medida que los factores políticos actúan como lo medular de los grandes bocetos del sistema procesal, al determinar el modelo que se adoptará, y de esta manera, las garantías que se resguardarán. Por eso, optar por un determinado sistema implica darle preponderancia a ciertos valores, y subsecuentemente desechar otros. Esa elección no es baladí, sino más bien responde al papel que se pretende que el Estado satisfaga en una sociedad, y a cómo se concibe la tarea de administrar justicia. Por lo mismo, Damaska apunta que "los regímenes políticos se legitiman a través de la administración de justicia que establecen. El diseño de los procedimientos es sensible a las variaciones particulares de la ideología imperante". ${ }^{4}$

Por tanto, es esencial considerar las circunstancias políticas que rodean al proceso, en tanto el modelo vigente es fruto de las ideologías que se buscan instaurar; y en particular, el ordenamiento es el retrato de los valores sociopolíticos que se intentan implementar en la sociedad. Por ejemplo, en los ordenamientos actuales no rigen sistemas puros, sino modelos mixtos que persiguen satisfacer los diversos intereses en juego. Precisamente el modelo penal chileno "se trata no solo de un sistema que procura insistentemente desvincular la verdad respecto del

\footnotetext{
${ }^{3}$ Foucault, Michel: "Microfísica del poder" [en línea]:

<cvirtual.filosofia.cu/almacen/libros/Foucault...Microfisica-del-Poder.../file> [consulta: 3 agosto 2011].

${ }^{4}$ DAmaska, Mirjam: Las caras de la justicia y el poder del Estado, análisis comparado del proceso legal, Santiago, Editorial Jurídica de Chile, 2000, p. 21.
} 
Cociña - La dinámica entre la búsqueda de la verdad y las convenciones probatorias...

poder, sino de un modelo que aspira a algo aún más profundo y todavía más revolucionario, a saber, a democratizar la verdad, es decir, a juzgar a base de criterios y razones que no se mantienen en las penumbras, sino que subyacen en la racionalidad". 5

Esta racionalidad a la que hace mención Peña no se traduce en que el proceso punitivo asegure en todos los casos que alcanzará una respuesta que se condiga con lo acaecido, sino implica que el proceso se estructurará de tal modo que garantice que la decisión sea justa, esto es, que la respuesta sea fruto de una construcción racional que se adecue a la determinación verídica de los supuestos fácticos que fundan la sentencia. Bajo esta perspectiva, Horvitz apunta que el proceso constituye "genuino mecanismo de legitimación retrospectiva del conflicto concreto y de su solución. La decisión se legitima retrospectivamente si y solo si ella se ajusta a la convención legal que establece con exactitud qué hechos deben considerarse como delito... un modelo penal garantista exige, tanto en el plano epistemológico como político, que la legitimidad de las decisiones penales se condicione a la verdad empírica de sus motivaciones, en el sentido de correspondencia lo más aproximada posible de la motivación con las normas aplicadas y los hechos juzgados". ${ }^{6}$

De ahí que la verdad se erija como un valor cardinal en el proceso penal, al posibilitar hablar de justicia de la decisión. Por lo mismo, constituye un valor que siempre se debe perseguir en el proceso, pues, y como afirma Ferrajoli en su conocida obra Derecho y Razón, "si una justicia penal completamente con verdad constituye una utopía, una justicia penal completamente sin verdad equivale a un sistema de arbitrariedad".

En este punto cabe precisar que si bien averiguar la verdad es un objetivo fundamental del proceso punitivo, y de la justicia de la decisión, no es la única finalidad que se persigue, debido a que el proceso penal además debe asegurar la paz jurídica, aplicando las normas a los supuestos para los cuales se previeron. De este modo el Derecho podrá motivar las conductas de los ciudadanos, en la medida que la sanción solo se aplicará cuando concurran los supuestos concebidos en la normativa.

Entonces la importancia del proceso penal no reside en su posibilidad de coacción frente a la inobservancia de la ley, sino en la capacidad de motivar las conductas de las personas, al otorgar una respuesta racional y fundada al conflicto. He así como no solo es posible que en el proceso se determine la verdad, sino también es necesario averiguar la misma para alcanzar una decisión judicial justa,

\footnotetext{
5 Peña, Carlos: "Los derechos humanos en el nuevo procedimiento penal" [en línea] $<$ http://mingaonline.uach.cl/pdf/revider/v11/art18.pdf >

${ }^{6}$ Horvitz, María Inés y López, Julián: Derecho procesal penal chileno, Santiago, Editorial Jurídica de Chile, 2002, p. 25.

${ }^{7}$ Ferrajoli, Luigi: Derecho y Razón: Teoría del garantismo penal, $5^{a}$ ed. Madrid, Trotta, 2001, p. 45.
} 
ya que en un proceso regido por el principio de legalidad las normas se deben aplicar a los supuestos para los que fueron concebidas. Es decir, en un Estado de Derecho "se requiere que las decisiones judiciales se sustenten en normas jurídicas aplicables al caso concreto, el que a su turno debe estar debidamente establecido en su dimensión factual, para que así el resultado no solo sea formalmente aceptable, sino intrínsecamente justo". 8

En este ámbito, la prueba juega un rol fundamental, al ser el medio por el que el proceso determina la verdad de los enunciados de hecho, esto es, al verificar si la proposición fáctica que constituye la condición de aplicación de la norma es verdadera o falsa. De ahí que, en términos de Marina Gascón, "el éxito de la institución de la prueba jurídica se produce cuando los enunciados sobre los hechos que se declaran probados son verdaderos, por lo que puede sostenerse que la función de la prueba es la determinación de la verdad sobre los hechos".? En esta misma línea, Jordi Ferrer, acentuando la importancia que conlleva la prueba en el proceso penal, manifiesta que "el objetivo institucional de la prueba en el proceso es la averiguación de la verdad. Y ello no puede ser de otra manera, ya que ese objetivo es estructuralmente necesario para que funcione el propio Derecho como mecanismo de motivación de la conducta". ${ }^{10}$

Ahora bien, si se consideran las limitaciones que presenta la prueba en el proceso, se tendrá que lo probado no se puede asimilar a lo verdadero, debido a que "conceptualmente cabe la posibilidad de que un enunciado esté probado y que, contemporáneamente, sea falso. Es más, nunca podemos tener la certeza racional de que un enunciado empírico es verdadero. Un enunciado será aceptable como verdadero si está suficientemente corroborado por los elementos de juicio existentes. Esta es, pues, una noción epistémica y objetiva de prueba. Y esto es lo mejor que podemos hacer para maximizar las probabilidades de correspondencia entre lo que se declara probado y lo verdaderamente ocurrido en el mundo". ${ }^{11}$

Desde esta perspectiva, la función epistemológica que se le atribuye a la prueba en el proceso punitivo se satisface en tanto se asume que el conocimiento que se va a alcanzar será relativo al contexto en el cual se inserta. Así, una proposición será verdadera si posee suficientes elementos de juicio a su favor que permitan declararla como probada. Por eso, en el proceso no se obtendrán verdades absolutas, pues la verdad que se va a alcanzar es relativa, contextual y aproximada a los elementos de juicio con que se cuenta.

\footnotetext{
${ }^{8}$ Taruffo, Michele: La prueba de los hechos, Milán, Trotta, 2002, p. 176.

9 Gascón, Marina: "La prueba judicial. Valoración racional y motivación” [en línea] <http:// www.uclm.es/postgrado.derecho/_02/web/materiales/filosofia/Prueba.pd> [última visita: 3 agosto 2011].

${ }^{10}$ Ferrer, Jordi: La valoración racional de la prueba, Madrid, Marcial Pons, 2007, p. 82.

11 Ibid., p. 20.
} 
Cociña - La dinámica entre la búsqueda de la verdad y las convenciones probatorias...

Particularmente, la indagación de la verdad es una finalidad primordial para el sistema penal, en la medida que constituye la manera de explicar lógicamente la justicia de la resolución judicial. Por lo mismo, no se debe renunciar a su determinación en el proceso, y en especial en el supuesto de condena, ya que averiguar la verdad le otorga racionalidad a la decisión. Entonces, independientemente de que la verdad que se alcance en el proceso sea aproximativa y contextual, no debe renunciarse a esta, pues las sentencias se legitiman en cuanto se condicen con la verdad. En efecto, la discusión no es respecto de si el proceso debe orientarse a la verdad, sino más bien a qué verdad se está haciendo referencia y bajo qué condiciones se puede alcanzar.

Considero, al igual que Taruffo, que "la verdad de un enunciado no viene reconducida directamente a la correspondencia con los eventos del mundo real, sino antes bien a la existencia de adecuadas justificaciones que pueden ser invocadas en apoyo y en confirmación de la veracidad del enunciado en cuestión. La justificación no coincide por tanto con la verdad del enunciado, sino antes bien aparece conectada con la verdad de él en cuanto la presupone". ${ }^{12}$

En consecuencia, se asume una noción epistémica de verdad como justificación de las proposiciones que se refieren a los hechos del mundo externo. De ahí que se dejen de lado concepciones que postulan que en el proceso se alcanzaría solo una verdad formal y aquellas que sostienen que la verdad se reduce al consenso prestado por los intervinientes en el proceso. A grandes rasgos, se prescinde de las primeras, pues omiten que la verdad a la que se está haciendo referencia no es una verdad absoluta en términos últimos. Ello no se puede configurar en las ciencias exactas, ni tampoco en el proceso penal. Creer lo contrario sería caer en una ingenuidad epistemológica. También se prescinde de las segundas, pues se estima que no es posible pretender, mediante el consenso, transformar verdadero lo que es falso, o falso lo que es verdadero. Si fuera así se debería admitir, por ejemplo, que la Tierra era plana, pues solo antes de Colón esa era la creencia de la época. Sin embargo, eso no es así, pues la verdad de una proposición no depende del acuerdo entre las partes, sino del modo cómo está constituido en el mundo el hecho que le es su objeto. ${ }^{13}$

La concepción epistémica de la verdad entiende que es posible que pueda darse un conocimiento válido y objetivo, en la medida que hay una realidad que es conocible de un modo racional, es decir, "es posible reconocer, sobre la base de conocimientos empíricos y de justificaciones lógicas adecuadas, cuando un enunciado es verdadero o falso sobre la base de la realidad que se pretende describir. En el contexto del proceso esto implica que se admita la posibilidad de

\footnotetext{
12 Taruffo, Michele: “¿Verdad Negociada?”, Revista de Derecho, 16 (1): 129-151, 2008, p. 132.

${ }^{13}$ No se efectuará un análisis de estas concepciones, pues escapa del objeto del presente artículo. Para más detalle vid., entre otros, Taruffo, Michele: ¿Verdad Negociada?, Revista de Derecho, 16 (1): 129-151, 2008.
} 
conseguir una determinación verídica de los hechos relevantes para la decisión, a través del empleo de adecuados métodos probatorios". ${ }^{14}$

En este contexto la prueba juega un rol esencial, en la medida que permite hablar de verdad en términos cognoscibles, al otorgarle al juzgador los elementos necesarios para determinar si cierta afirmación, referente a un acontecimiento, es verdadera o falsa. Y no solo la prueba como medio de verificación es fundamental en el proceso penal, sino también la valoración que se realice de esta y el estándar probatorio, en tanto determina el umbral de suficiencia exigido al juzgador para tener por probadas los enunciados.

Sobre el particular, Accatino afirma que el sistema probatorio nacional se centra en el supuesto de que la finalidad de búsqueda de la verdad puede alcanzarse de mejor modo si el juez "puede acceder a todas las pruebas potencialmente relevantes (sin exclusiones fundadas en la posibilidad de sobrevaloración) y que confía sobre todo en la fundamentación de las decisiones sobre la prueba como garantía y herramienta de control de racionalidad y su corrección de acuerdo con los estándares probatorios fijados por el derecho". ${ }^{15} \mathrm{En}$ este sentido, la motivación de la sentencia al exigir la verificación de los enunciados fácticos alegados en juicio para alcanzar una decisión jurídica, asegura de cierto modo que el resultado que se alcance no solo resulte aceptable formalmente, sino también sea una decisión intrínsecamente justa.

Considerando lo anterior, a continuación se analizará la relación existente entre la averiguación de la verdad y las convenciones probatorias.

\section{La dinámica entre las convenciones probatorias y la averiguación de la verdad en el proceso penal}

Para precisar qué es lo que se considera problemático, esto es, por qué se introducen las convenciones probatorias en el marco teórico del concepto de verdad, a priori es necesario resolver algunas interrogantes básicas como ¿qué son las convenciones probatorias?, ¿cuáles son sus características esenciales?, ¿cuál es el fundamento de su incorporación en el ordenamiento penal? Dar respuesta a estas preguntas permitirá comprender el rol que cumplen las convenciones en el proceso penal y reflexionar sobre cómo se concilian con la finalidad de alcanzar la verdad.

En primer lugar las convenciones pueden ser definidas tanto a nivel legal como doctrinario. El legislador nacional no entrega un significado exhaustivo de lo que constituyen e implican, sino únicamente hace referencia a sus características

\footnotetext{
${ }^{14}$ Ibid., p. 134.

15 Accatino, Daniela: “Certezas, dudas y propuestas en torno al estándar de la prueba penal”, Revista de Derecho de la Pontificia Universidad Católica de Valparaíso, 37: 438-511, 2011.
} 
Cociña - La dinámica entre la búsqueda de la verdad y las convenciones probatorias...

fundamentales. Específicamente, el artículo 275 del Código Procesal Penal, denominado convenciones probatorias, señala que "durante la audiencia, el fiscal, el querellante, si lo hubiere, y el imputado podrán solicitar en conjunto al juez de garantía que dé por acreditados ciertos hechos que no podrán ser discutidos en el juicio oral”.

En efecto, la legislación nacional concibe a las convenciones probatorias como una herramienta que permite al juez de garantía, si existiere consenso entre los intervinientes, sustraer del período probatorio determinados enunciados. En igual sentido se han expresado Rodrigo Cerda o María Inés Horvitz -teóricos que han estudiado esta materia-, quienes han sido contestes en catalogar a las convenciones probatorias como acuerdos adoptados en la audiencia de preparación del juicio oral por el fiscal -el querellante si lo hubiere- con el imputado, autorizados por el juez de garantía, destinados a dar por aceptados determinados hechos, con el fin de no ser objeto de discusión en el juicio oral.

Ahora en cuanto a las características de las convenciones probatorias, tanto de la disposición legal como de su noción doctrinaria, se aprecian cuatro características definitorias. La primera está dada porque la convención probatoria constituye un acuerdo entre los intervinientes del proceso penal. Justamente, la incorporación en el sistema punitivo de un convenio entre los sujetos involucrados resulta un concepto ajeno a lo penal, pues en este ámbito las decisiones las adopta el juez, con independencia de lo que estimen los intervinientes. Por eso, las convenciones probatorias realizan un giro no menor en la materia, al posibilitar que mediante un pacto se impida la discusión futura de ciertos hechos.

El segundo elemento que identifica a las convenciones es que recaen sobre afirmaciones fácticas, es decir, no sobre hechos, ya que los acontecimientos ocurren o no, mientras que las aseveraciones respecto de estos, pueden ser verdaderas o falsas.

En tercer término, las convenciones probatorias dispensan de probar aquellas alegaciones sobre las que existe acuerdo. De este modo se incorporan al ordenamiento penal para evitar discusiones sobre puntos de hecho que no se encuentren debatidos. Por eso, se excluyen del objeto de la discusión probatoria y de la posterior fijación por parte del tribunal oral. Así, las convenciones irían directamente desde el auto de apertura, dictado en la audiencia de preparación de juicio oral, a la sentencia definitiva. Ahora bien, este "salto" que efectúan las convenciones no está exento de debate, en la medida que el juicio oral constituye el ethos del proceso penal, y específicamente la prueba es esencial para efectos de verificar si las proposiciones alegadas en juicio se condicen con los supuestos fácticos que la normativa previó.

En cuarto y último lugar, las convenciones probatorias se caracterizan por requerir aprobación judicial. Esta exigencia se establece en la medida que es vital 
REJ - Revista de Estudios de la Justicia - No 18 - Año 2013

que exista un control que verifique que lo convenido por los intervinientes en las convenciones se condiga con las afirmaciones efectuadas en la audiencia.

Una vez delineadas las características de las convenciones, es interesante tratar el reconocimiento normativo que han tenido las convenciones en el ordenamiento interno. Si se estudia la historia de la ley, se percatará que el anteproyecto y el mensaje del Código del ramo no consideran la actual disposición 275 del Código Procesal Penal; tampoco esta figura se contempló por la Cámara de Diputados, sino solamente se aprecia en la Cámara Alta del Congreso el ánimo de incorporar esta nueva herramienta al sistema penal. Intención que finalmente se concretó en la quinta sesión de la Comisión de Constitución del Senado.

Al recorrer el camino legislativo que tuvo la convención probatoria, es interesante examinar, ¿por qué ahora se incorporan las convenciones probatorias?

Esta interrogante, en parte, puede ser satisfecha si se consideran los principios que inspiraron la Reforma Procesal Penal en Chile; es decir, si se tiene en cuenta que el nuevo sistema punitivo nacional debe consagrar, entre otros, la imparcialidad, la transparencia, la inmediación, la oralidad, la rapidez, la eficiencia, la concentración y la protección de las víctimas y de los testigos. Estas máximas denotan que las convenciones fueron incorporadas para simplificar el proceso, de forma de excluir del debate lo que no se encuentra controvertido. En este sentido, las convenciones se adecuan al principio de la economía procesal, que busca aprovechar los recursos disponibles del mejor modo posible. Así, si existe consenso entre los intervinientes respecto de hechos no controvertidos y aprobación judicial, el resultado es dar por acreditado los enunciados, impidiendo su discusión futura. En otras palabras, las convenciones permiten que los intervinientes disminuyan el tiempo en que "colgará la espada de Damocles" sobre la cabeza del imputado.

Particularmente esta restricción en la discusión se debe a que las convenciones se enmarcan dentro de la lógica de que la jurisdicción penal debe ser capaz de entregar una respuesta razonable en un tiempo prudente, de manera de otorgar seguridad sobre la vigencia de la ley y hacer tangible el aforismo romano que reza "una justicia que tarda, no es justicia". En efecto, el proceso penal debe dar una respuesta oportuna a los conflictos que se le presentan; de modo que frente a diferentes problemáticas exista una variedad de soluciones. El establecimiento de diferentes procedimientos en el ámbito punitivo se configura para evitar que el sistema colapse frente al alto número de casos que debe resolver. Así, la convención probatoria se incorpora en la esfera punitiva para depurar y delimitar la discusión que será puesta en conocimiento del tribunal oral en lo penal.

Sin embargo, la lógica de sustraer de la discusión del juicio oral determinados enunciados fácticos y darlos por acreditados, ineludiblemente implica renunciar a configurar la relación con lo probado, y a su vez, se traduce en 
Cociña - La dinámica entre la búsqueda de la verdad y las convenciones probatorias...

desistir en algún grado -al menos- a la determinación de la verdad. Ello no deja de ser problemático, pues si se considera que uno de los propósitos esenciales del proceso penal es fundar la sentencia en la determinación de la verdad, esto generaría al menos una tensión con las convenciones probatorias, ya que de la idea misma de convención fluye una comprensión de lo acreditado, como dado tan solo en virtud de dicho acuerdo, y no según lo probado en el juicio.

Negarse a ver la tensión que se produce, implica no hacerse cargo del problema y se reduce a la buena intención de lograr una conciliación, donde lo que hay es conflicto; ya que cuando los intervinientes asumen un rol en la construcción de la prueba, eso se traduce en la comprensión de la verdad como una verdad consensual; es decir, lo verdadero pasa a ser lo consensuado como tal, con cierta prescindencia de la relación entre lo acordado y la realidad.

Si se efectúa un paralelo con los demás mecanismos de negociación insertos en el ámbito penal, esta nueva herramienta, al igual que otras instituciones similares, conllevaría "en nuestra estructura procesal nada menos que el prescindir sistemáticamente de la búsqueda de la verdad; esa es precisamente su importancia sociológica procesal". ${ }^{16}$ En consecuencia, este nuevo mecanismo envolvería algún grado de renuncia a la verdad como tal, y su reemplazo por la verdad como acuerdo intersubjetivo, debido que ahora la decisión del juez recae sobre lo consensuado como real. Eso es - de hecho al menos- una mediatización del recurso a la verdad, porque entre lo real y lo probado se encuentra lo consensuado.

$\mathrm{Al}$ respecto, Rodrigo Cerda en su libro Etapa Intermedia, juicio oral y recursos sostiene que la convención probatoria "reafirma la idea de que en este nuevo sistema la verdad histórica puede ser redefinida por las partes, ya sea de común acuerdo o a través de las teorías del caso". ${ }^{17}$ Bajo esta lógica, con las convenciones se estaría adhiriendo a una postura consensualista, donde la verdad únicamente podrá explicarse "echando mano de la dimensión pragmática del lenguaje... Y, así verdad significará el sentido del empleo de los enunciados en afirmaciones cuyo referente 'práxico' sea una determinada clase de actos de habla. En otras palabras, una acción es significativa, es decir, puede alcanzar el valor de verdad cuando se integra en un contexto comunicativo". ${ }^{18}$

En este punto, María Inés Horvitz efectúa una pertinente aclaración, al afirmar que la noción consensualista de Habermas y de Apel se postula desde un "paradigma epistemológico trascendental, en el sentido de que sus exigencias se

\footnotetext{
16 Hassemer W.: "La verdad y la búsqueda de la verdad en el proceso penal" [en línea] $<$ http://www.ucab.edu.ve/tl_files/Derecho/Archivos/Varios/la $\% 20$ verdad $\% 20 y \% 201 \mathrm{a} \% 20$ busqu eda $\% 20 \mathrm{de} \% 201 \mathrm{a} \% 20$ verdad $\% 20$ en $\% 20$ el $\% 20$ proceso $\% 20$ penal $\% 20 \% 28$ winfried $\% 20$ hassemer $\% 29$ .pdf>, p. 12.

${ }^{17}$ Cerda, Rodrigo: Etapa intermedia, juicio oraly recursos, Librotecnia, Santiago, 2003, p. 44.

18 González, Graciano: "La teoría consensual de la verdad en J. Habermas" [en línea] < http://fsmorente.filos.ucm.es/docentes/arnaiz/textos/Habermas.pdf>.
} 
hallan presupuestas, incoactivamente, en toda clase de comunicación, esto es, en un discurso libre de dominación, propio de la ética discursiva y, por lo tanto, no aplicable a los discursos prácticos o institucionales (como el del proceso penal), sino como suposición contrafáctica. Por ello, porque se da por supuesto que dicha situación ideal no ocurre nunca en el proceso penal, es que sirve esta teoría como instancia crítica frente a las pretensiones de verdad o de validez que se plantean respecto de cualquier discurso real". ${ }^{19}$

Atendido lo anterior, se hace vital no confundir "las posiciones que postulan el consenso no cognitivo, basado en la coherencia contextual de la narración $\mathrm{o}$ en consideraciones meramente táctico-procesales como base legitimante del proceso penal y la sentencia con aquellas como la concepción consensualista de la verdad sostenida por Habermas, que postulan el consenso con valor cognitivo como finalidad del proceso, esto es, una verdad basada en un consenso racionalmente fundado, como adaequatio intellectus et rei. ${ }^{20}$

En este sentido, la hipótesis habermasiana se instaura a partir de la idea de verdad inscrita en una estructura de comunicación, es decir, para este filósofo, la verdad se asienta mediante el discurso en un mundo ideal, a diferencia de lo que acontece en el ámbito procesal, donde lo coercitivo juega un rol fundamental. De ahí que en este punto se prescindirá de la teoría de Habermas, en el entendido de que su concepción al configurarse especialmente respecto de la hipótesis de los actos de habla, resulta ajena a la esfera procesal penal. De este modo, la crítica se centrará en aquella teoría de la verdad que se establece como simple pacto entre los intervinientes fundado en motivos estratégico-judiciales. Ello en la medida que el consenso que se alcanza en esa concepción lo es, con independencia de si la determinación verdad se condice o no con los hechos acaecidos en el mundo externo y que son reconocidos en la normativa.

Una vez esclarecido lo anterior, es esencial advertir que la incorporación de las convenciones probatorias en el sistema punitivo resulta problemática, tanto a nivel teórico como práctico. Desde un plano teórico es conflictiva, ya que cuando la verdad se entiende como construcción a partir de un acuerdo intersubjetivo, lo que se hace es contrastar concepciones sobre lo real y no acudir a lo verificado. De allí que la construcción de la verdad se establezca como un vínculo entre sujetosujeto, ya que basta con el acuerdo entre los intervinientes para dar por acreditado lo afirmado.

La idea misma de convenciones en el seno de un sistema acusatorio involucra una cierta transacción que prescinde de la comprensión de la verdad como realidad objetiva por una realidad intersubjetivamente construida. Eso, sin duda no deja de ser polémico, pues las convenciones al fundarse en lo consensual

\footnotetext{
${ }^{19}$ Horvitz y López: ob. cit. (nota 6), p.515.

${ }^{20}$ Ibid. p. 42.
} 
Cociña - La dinámica entre la búsqueda de la verdad y las convenciones probatorias...

se traducen en desistir en cierto grado a la determinación de la verdad en el proceso penal.

Sin embargo, esta dinámica que se genera en el proceso punitivo con las convenciones no es per se negativa, si se considera, por ejemplo, que en el sistema anterior donde el órgano que investigaba era el mismo que juzgaba, la búsqueda de la verdad envolvía una suerte de verdad a cualquier precio, lo que entraba en pugna con las garantías individuales. Es básicamente a base de la protección de dichas garantías esenciales que se sustituye el modelo. Ahora, el reemplazo del régimen procesal tiene un costo, que se manifiesta en negarse a alcanzar siempre y en todo caso la verdad. Un caso paradigmático del precio que debe pagar el Estado de Derecho es la exclusión de la prueba ilícita, institución donde existe una clara renuncia a la verdad, en pos del respeto a las garantías fundamentales de los individuos.

Además, si se tienen en cuenta las limitaciones que existen en el proceso punitivo para alcanzar a la verdad, ya sea a nivel de recursos o de tiempo, se apreciará que las convenciones probatorias se enmarcan en la lógica del proceso penal vigente en Chile; esto debido a que la solución acusatoria, forzosamente implica, por sus variadas restricciones y mecanismos, renunciar - en cierta medida - a la finalidad de averiguar la verdad y las convenciones se incorporan en el mismo sentido, al posibilitar que se configure en el ordenamiento nacional una verdad que se remite a lo pactado por los intervinientes.

Bajo esta misma lógica se establece en el sistema penal el estándar probatorio de más allá de toda duda razonable, pues y como afirma Accatino, en este estándar "lo que está en juego es evitar especialmente un tipo de error, el falso positivo (declarar probada una proposición falsa), aun a costa de elevar el riesgo de falsos negativos (declarar no probada una proposición verdadera). Se trata, como se puede observar, de un fin diferente al de la pura averiguación de la verdad y que está parcialmente en tensión con este". ${ }^{21}$

Esta renuncia a la indagación de la verdad en el sistema punitivo se concibe en el entendido de que en el actual proceso penal se encuentran diversos intereses en juego que pugnan entre sí por imponerse, y deben ser armonizados según los principios que rigen el ordenamiento jurídico. De este modo, si bien se acepta que es fundamental que el proceso se oriente a la búsqueda de la verdad, se comprende que esta no puede ser conseguida a cualquier precio. Admitir lo contrario sería socavar las bases en las cuales se sustenta el Estado de Derecho, ya que en la configuración del proceso la indagación de la verdad debe conjugarse con otros valores, como el respeto de las garantías fundamentales y la igualdad de los intervinientes, de manera de que el proceso sea capaz de satisfacer esas máximas en conjunto con otros intereses, como la celeridad y la economía procesal. En un mismo sentido se manifiesta Taruffo, al señalar que "la eficiencia del

21 Accatino: ob. cit. (nota 16). 
procedimiento y la economía de las actividades procesales deberían ser compatibles con la actuación de otros valores inherentes al proceso y a la administración de justicia que no son menos importantes, y por lo tanto no pueden ser sacrificados a priori, como la justicia de las decisiones judiciales". ${ }^{22}$ Por consiguiente, el ordenamiento punitivo debe erigirse, a la vez, como un mecanismo racional y eficiente de atribución de responsabilidad.

En este punto es importante considerar que "las reglas que persiguen la garantía de esos otros fines del proceso pueden imponer algún sacrificio epistemológico, en el sentido de que puedan ser contraproducentes para el objetivo de la averiguación de la verdad. Esto no implica que sea imposible alcanzar una determinación verdadera de los hechos ocurridos, sino más modestamente, que las probabilidades de que ello ocurra, debido al conjunto de elementos de juicio, serán más pobres, serán también más bajas. Y siendo consciente de ese coste, el legislador deberá decidir en cada caso de conflicto entre la maximización de los fines epistemológicos y de cualquier otro que se quiera proteger en qué medida se sacrifican unos y otros". ${ }^{23}$ En el caso de las convenciones probatorias, el legislador opta por priorizar la eficiencia del proceso frente a lo epistemológico. Esa elección no es menor, pues un déficit en la determinación de la verdad de los hechos incide en la justicia de la decisión. De ahí que las convenciones no solo conlleven un marcado carácter funcional o economía procesal, sino también un factor ideológico importante, en virtud de la concepción de proceso que se asume en el ámbito penal. Ello pues, la lógica de que los intervinientes pueden determinar qué debería ser probado o que debería ser tenido como verdadero para efectos de la decisión, aleja al proceso punitivo de la esfera pública, situándolo en un ámbito privativo de las partes. Lo anterior es relevante, ya que lo que está en juego es la finalidad que debe perseguir el proceso, y en resumidas cuentas, cómo se concibe el proceso penal. En este punto no se debe olvidar la radicalidad que envuelve la decisión judicial, no solo para los intervinientes, sino para la sociedad. Por eso la verdad a alcanzar para condenar no es un bien particular, sino público. En este contexto, las convenciones probatorias, al posibilitar que los intervinientes puedan determinar qué se tiene por verdadero en la decisión, se apartarían de la naturaleza pública que caracteriza al proceso penal y envolverían un giro ideológico en la materia. ${ }^{24}$

Sin perjuicio de lo anterior, el legislador nacional bajo la lógica de que la celeridad constituye un componente de la justicia, decidió incorporar en el ordenamiento jurídico instituciones tales como las convenciones probatorias y el procedimiento abreviado. Como se señaló, las convenciones son una herramienta de simplificación procesal, que frente a la no controversia de determinados hechos,

\footnotetext{
22 Taruffo: ob. cit. (nota 9), p. 139.

${ }^{23}$ Ferrer: ob. cit. (nota 11), p. 78.

${ }^{24}$ Las consecuencias que se pueden derivar de la presente discusión excede las competencias de este artículo, por lo que la disyuntiva que se genera con la asunción de esta concepción en el proceso penal solo se dejará planteada.
} 
Cociña - La dinámica entre la búsqueda de la verdad y las convenciones probatorias...

los da por acreditado. Mientras, el segundo mecanismo dispensa al juicio de la prueba, en virtud de que el imputado asume la veracidad de las afirmaciones de los hechos, y sujeta al juez -en el caso de dictar sentencia condenatoria- a que restringa la pena a cierto lapso de años. He ahí como se percata que a diferencia del procedimiento abreviado, las convenciones implican una aceleración del proceso, pero no la renuncia al juicio oral, pues aunque en estas exista una importante intervención de la voluntad de los intervinientes, solo persiguen reducir el tiempo de duración de los procedimientos. Por lo tanto, si bien las convenciones probatorias se asimilan al procedimiento abreviado, al inspirarse en razones de carácter utilitario, se diferencian -además de lo señalado- en que en las convenciones basta la aceptación de los enunciados por parte del acusado, es decir, el juez de garantía en la audiencia de preparación no tiene el deber de comprobar que las proposiciones sobre hechos se basen en circunstancia alguna de la investigación.

En esta línea, Horvitz reflexiona que si el legislador nacional evaluó conveniente "la aplicabilidad del procedimiento abreviado a delitos graves y planteó un límite para su procedencia, es claro... que las convenciones probatorias en el procedimiento ordinario, sobre hechos esenciales para el establecimiento de la responsabilidad criminal, no resultan ni legítimas ni procedentes". ${ }^{25}$

Precisar lo anterior es primordial, pues si bien se admite que el proceso penal incorpora excepciones contraepistemológicas con la finalidad de proteger otros valores considerados jurídicamente relevantes, se debe determinar hasta qué punto se está dispuesto a sacrificar la averiguación de la verdad en pos de la eficiencia. Ello, en este caso particular se traduce en hasta qué punto las convenciones probatorias se extenderán, esto es, en determinar si las convenciones pueden recaer sobre todos los hechos de la acusación, solamente respecto del suceso principal, u otras alternativas.

Según mi parecer, si bien la ley no establece ex ante ningún límite en cuanto al ámbito de aplicación de las convenciones, es ineludible que se fijen límites al establecimiento de estas en el proceso penal, ya que la respuesta judicial que se adopte debe condecirse con lo probado, de modo tal que se atenga al ideal de justicia que demanda todo ordenamiento. Por lo mismo, la convención probatoria debe estar delimitada, pues no resultaría sensato dispensar al proceso de la prueba, en la medida que esta constituye el sustrato primordial que utiliza el juez para construir su sentencia y es lo que le otorga legitimidad a la decisión judicial, en tanto se condice con el supuesto fáctico que previó la norma.

Asimismo, la prueba resulta esencial en el proceso, en tanto objetiviza el estándar probatorio establecido por el legislador en esta materia, dotándolo de contenido, al exigir que el umbral de suficiencia requerido se atenga a la presencia de elementos de pruebas disponibles. De ahí que las convenciones probatorias al

\footnotetext{
${ }^{25}$ Horvitz y López: ob. cit. (nota 6), p. 44.
} 
prescindir de la prueba no resulten compatibles con el estándar de prueba de más allá de toda duda razonable, ya que este para evaluar si las pruebas disponibles, valoradas racionalmente, son suficientes para considerarlas por probadas se atiene a las pruebas aportadas al proceso.

Por consiguiente, se debe desechar la posibilidad de que mediante esta herramienta se den por establecidas todas las circunstancias fácticas que conforman el comportamiento del acusado, del tipo penal, de la antijuricidad y de la culpabilidad. Ello no se puede aceptar, pues independiente de que la ley no configure restricciones al respecto, "las limitaciones surgen del fundamento de legitimación del juicio oral, único rito que permite que operen todas las garantías procesales, cuya función principal es asegurar que la decisión que se adopte judicialmente, lo sea de un modo cognoscitivo, y no meramente convencional". ${ }^{26}$

Si bien se reconoce la necesidad de delimitar las convenciones probatorias, no existe claridad de cómo configurar las restricciones. De ahí que la solución del caso concreto será una cuestión que quede al arbitrio del juez. Eso sí, el juzgador en su tarea debe considerar que las convenciones probatorias únicamente pueden recaer sobre los enunciados de hechos que conforman el objeto del juicio oral, esto es, sobre aspectos de fondo. Además, el juez en su actuar debe tener presente que mediante las convenciones no puede dar por establecidos todos los enunciados fácticos que configuran la responsabilidad punitiva. En consecuencia, el Tribunal Oral no podrá condenar a una persona exclusivamente por lo acordado en las convenciones, ya que tal como lo establece el inciso tercero del artículo 340 del Código Procesal Penal se prohíbe condenar a una persona con el solo mérito de su propia declaración.

En consecuencia, el juzgador para alcanzar su convicción deberá justificar su decisión basándose en las pruebas aportadas al proceso. Así, la exigencia de prueba al tener que verificar los enunciados fácticos para alcanzar una decisión jurídica, asegura de cierto modo que la solución obtenida será coherente. De esta forma, la facultad de control del sentenciador no pierde fuerza, en la medida que por medio de la libre valoración de la prueba puede sopesar lo pactado en las convenciones con las pruebas rendidas, manteniendo su rol de garante del proceso.

Lo anterior se plantea en tanto puede acontecer que en el juicio oral se rinda prueba que no sea coincidente con lo establecido por los intervinientes en la convención probatoria, entonces ¿cómo se resuelve aquello?, ¿qué ocurre si se aprueba una convención, y posteriormente al presentarse una prueba esta desvirtúa o contradice lo pactado en la convención?, ¿el tribunal oral se encuentra obligado a respetar lo acordado por los intervinientes y aprobado por el juez de garantía $?^{27}$ Es

\footnotetext{
${ }^{26}$ Ibid.

${ }^{27}$ Por ejemplo ¿qué pasa si en el auto de apertura se acuerda que la causa de la muerte fue por infarto cardíaco y el perito que confeccionó el informe de defunción señala que la muerte se debió
} 
Cociña - La dinámica entre la búsqueda de la verdad y las convenciones probatorias...

primordial responder a estas interrogantes, no solo porque estas situaciones pueden darse en la práctica, sino más bien porque resulta vital que esta nueva herramienta sea coherente con la función del proceso penal.

$\mathrm{Al}$ respecto, Horvitz asevera que derivar que las convenciones probatorias "son vinculantes para el tribunal constituye un salto ilógico sin fundamento alguno, pues no existe ninguna norma que las sustraiga del proceso valorativo a que se refiere el artículo 297 Código Procesal Penal. Solo podría afirmarse, en consecuencia, que tales hechos deben ser objeto de valoración en la sentencia. Nada más". ${ }^{28}$

Según mi parecer, quien está llamado a resolver no puede verse compelido por un acuerdo de los intervinientes que establece como dado determinados enunciados fácticos que no se corresponden con lo probado en el juicio oral. Por consiguiente, el Tribunal Oral no puede obligarse a lo estipulado en las convenciones probatorias, debido a que los sentenciadores tienen libertad para fijar los hechos sometidos a convención o desecharlos, por estimar que no se condicen con las demás pruebas aportadas en juicio.

En este sentido, Guillermo Ormazábal reflexiona: “¿en qué medida es el juez libre para fundar jurídicamente la sentencia de modo diverso al que las partes fijaron como coordenadas o marco jurídico del debate?... Tratándose de inquirir sobre la extensión y límites de la actividad enjuiciadora de los tribunales, la cuestión remite de lleno al tratamiento sobre el objeto del proceso. Y ya en este ámbito, el problema no radica ni en los límites subjetivos del enjuiciamiento ni está relacionado con el objeto o contenido de la tutela pretendida, sino que versa sobre el problema de la fundamentación". ${ }^{29}$ Así, la libre valoración judicial dice relación con la exigencia de motivación, en el sentido de que cuando el juez considera que lo sustentado por los intervinientes no se atiene a lo verificado en el juicio, debe dar razones de su apreciación, pues si bien tiene libertad para valorar los hechos, debe proporcionar los elementos necesarios para que la ciudadanía pueda reproducir su razonamiento.

Por lo tanto, las convenciones probatorias no serían vinculantes para el juzgador, debido a que el tribunal solo se encuentra obligado en su tarea jurisdiccional a atenerse a la sana crítica. Por eso, si el juez no concuerda con las convenciones pactadas, puede desecharlas, argumentando adecuadamente su rechazo. Eso es así, pues el arribo a una decisión judicial debe ser fruto de un razonamiento que se asiente en la lógica, los conocimientos científicamente afianzados y las máximas de experiencias. Por lo mismo, si según el tribunal lo

\footnotetext{
a envenenamiento? o ¿qué acontece si se pactó que el robo fue con fuerza, y los testigos manifiestan que los candados no fueron forzados?

${ }^{28}$ Horvitz y López: ob. cit. (nota 6), p. 42.

${ }^{29}$ Ormazábal, Guillermo: Iura novit curia. La vinculación del juez a la calificación jurídica de la demanda, Ediciones Jurídicas y Sociales, Madrid, 2007, p.17.
} 
acordado por los intervinientes no se atiene a estos criterios, es libre para descartar las convenciones. En similar sentido se manifiesta Taruffo, al señalar que "cuando el tribunal considera que ninguna de las historias ofrecidas por las partes ha sido sustentada por pruebas adecuadas, articulará una historia diferente basada en una reconstrucción autónoma y original de los hechos del caso, que tendrá que estar fundada en las pruebas que el tribunal ha tomado en consideración". ${ }^{30}$

Entonces, el proceso penal por medio de la prueba le entrega al juez mecanismos que le permiten verificar que lo establecido por los intervinientes se corresponda con los supuestos fácticos previstos en la normativa, y en caso contrario -si se rinde prueba que desvirtúa lo acordado-, desechar las convenciones. De ahí que surge la duda ¿para qué se incorpora la convención probatoria en el proceso punitivo chileno?

Según Horvitz, esta herramienta "tiene como única finalidad evitar que ciertos hechos invocados por las partes deban ser probados en el juicio, a través de los medios de prueba contemplados en la ley, si no existe controversia sobre su existencia" "31. En consecuencia, las convenciones se incorporarían en el ordenamiento punitivo con el objeto de simplificación procesal, o sea, para acortar la discusión respecto de proposiciones sobre acontecimientos que no se encuentran controvertidas.

Sin embargo, es importante considerar que aquello que se concibió como una mera simplificación del proceso, termina produciendo consecuencias complejas, como por ejemplo, descartar la confrontación entre los intervinientes. Esta supresión del debate incide en que las convenciones probatorias sean percibidas como "peligrosas puesto que abren la puerta a la manipulación de los hechos, a que se presenten las historias diseñadas para los intereses de quién las presenta, y no las más verídicas conforme a la correspondencia con lo sucedido. Peligroso claro, porque de aceptarse estas historias, se abre un camino sin regreso respecto de la averiguación de la verdad". ${ }^{32}$

En un mismo sentido, Damaska apunta a la complejidad de determinar fidedignamente los acontecimientos si estos resultan establecidos por los intervinientes. Sobre el particular, este teórico reflexiona: "¿pero qué hay de la exactitud de la determinación de los hechos comprobados en el proceso dominado por las partes? En tanto que los litigantes, actuando en su propio interés, no carecen de incentivos para actuar, también pueden sentirse motivados a ocultar la

\footnotetext{
30 Taruffo, Michele: "Narrativas judiciales" [en línea] <http://www.scielo.cl/scielo.php?pid=S071809502007000100010\&script $=$ sci_arttext $>$

${ }^{31}$ Horvitz y López: ob.cit. (nota 6), p. 42.

${ }^{32}$ Fusch, Andrés: Consideraciones teóricas y prácticas sobre la relación entre proceso, prueba y verdad. Editorial Metropolitana, Santiago, 2010, p. 73.
} 
Cociña - La dinámica entre la búsqueda de la verdad y las convenciones probatorias...

verdad. Una hábil orquestación de las pruebas más bien puede obscurecer antes que clarificar lo que ha ocurrido en la realidad". ${ }^{33}$

Por lo mismo, la doctrina ha sido conteste en destacar el papel que cumple la confrontación entre la acusación y la defensa, como mecanismo para alcanzar la verdad en el proceso penal; ello en el entendido de que una concepción más "dialéctica", propia del acusatorio, con dos partes enfrentadas intentando convencer al juez, acerca en mayor medida a la verdad, al existir otra tesis con la cual contrastar una postura. No obstante, Félix Herzog estima que "no se puede esperar que la verdad surja de la contradicción entre la acusación y la defensa, sino que en el proceso penal influyen cuestiones de poder social y político que solo pueden resolverse mediante el compromiso. Ya no sirve el principio de legalidad procesal, sino que se negocia a partir de una distribución políticamente inteligente de los recursos de la pretensión punitiva estatal". ${ }^{34}$

Por su parte, María Inés Horvitz afirma que "la pretendida igualdad de las partes al momento de la negociación es una ficción. Las instancias consensuales terminan por resultar, en manos del Estado, funcionales al modelo al cual sirven, consolidando la respuesta punitiva propia del derecho penal inquisitivo", ${ }^{35}$ en tanto prevalece una noción eficientista del proceso, por sobre una concepción garantista del sistema penal. De ahí que Horvitz advierta que "un sistema de enjuiciamiento criminal en el que el Estado ya no persigue el establecimiento de la verdad, sino que la terminación anticipada del procedimiento basada en un consenso entre partes desiguales se transforma inexorablemente en un sistema neo-inquisitivo". ${ }^{36}$

Reafirmando lo anterior, Luigi Ferrajoli sostiene que "ningún consenso puede valer como criterio de formación de la prueba. Las garantías de los derechos no son derogables ni disponibles". ${ }^{37}$ Por lo mismo, en el sistema penal las negociaciones encajan de muy mala forma, pues con tal de acortar los procedimientos, los mecanismos consensuales ahorran costos y tiempos del proceso, con la consecuente merma en las garantías de los intervinientes. Ello produce tensión al tranzar en la legitimidad que envuelve la decisión judicial.

Junto con la intrínseca desigualdad del imputado frente a la persecución penal y las marcadas distorsiones que se derivan, se agrega que el carácter que debe guiar al Ministerio Público debe ser neutral, es decir, el fiscal no solo debe investigar aquello que incrimina al imputado, sino también indagar con el mismo ahínco aquello que lo absuelve. Sin embargo, lo que se concibió como un

\footnotetext{
${ }_{33}$ Damaska, Mirjam: Las caras de la justicia y el poder del Estado, análisis comparado del proceso legal. Editorial Jurídica de Chile, Santiago, 2000, p. 211.

${ }^{34}$ Herzog, Félix: "La crisis de los principios espirituales y sociales del proceso penal reformado". Revista Ius et Praxis, 15 (1): 375- 386, 2009.

${ }^{35}$ Horvitz y López: ob. cit. (nota 6), p. 516.

${ }^{36}$ Ibid., p. 514.

${ }^{37}$ Ferrajoli, Luigi: Derechos y Garantías, La ley del más débil. Madrid, Trotta, 2001, p. 27.
} 
organismo objetivo y acorde a las garantías esenciales ${ }^{38}$ no se tradujo exactamente así, pues si se observa el escenario actual se advertirá que el Ministerio Público mayoritariamente investiga aquello que le sirve para inculpar. ${ }^{39}$

Esta percepción del Ministerio Público fue avizorada hace décadas por Francesco Carnelutti, quien postuló que el proceso penal es un péndulo, donde el Ministerio Público representa un extremo, el imputado el otro, y en el medio está el juez, quien debe decidir. Así, el fiscal al instaurarse como interviniente en el proceso punitivo pierde objetividad. En un mismo sentido se expresa Alberto Bovino al plantear que constituye una ficción creer que el fiscal actúa objetivamente, ya que "no puede existir una persecución objetiva por parte de quien es, precisamente, encargado de perseguir. No puede imponerse al fiscal una tarea imposible, esto es, no puede esperarse que quien representa al interés persecutorio actúe... de modo neutral, tratando de conciliar ese interés con el del imputado que resiste la imputación". ${ }^{40}$ Por lo mismo, Julio Maier argumenta que el papel del Ministerio Público, "su posición institucional, su organización y su tarea en el procedimiento seguirán siendo conflictivas y motivo de debates ásperos que sin resolver el problema primario, sólo posibilitarán soluciones coyunturales, según la preferencia política del legislador o del jurista, esto es, soluciones de compromiso dentro de un sistema que, en sí, es caótico". ${ }^{41}$

Esta visión crítica y escéptica sobre la labor de los fiscales no exclusivamente se debe a las presiones políticas, sino también responde a su misma orgánica, que establece mecanismos de eficiencia y bonos de productividad. Y si a estos incentivos perversos se le agrega la excesiva carga laboral con que cuentan, se tendrá como resultado que los fiscales, más que propender a una indagación

\footnotetext{
38 Al respecto, Von Mühler, a mediados del siglo XIX, representó al Ministerio Público como el "custodio de las leyes". Tiempo después, Von Savigny en conjunto con Uhden, en su famoso dictamen describió al fiscal como "presidido por la ley y la verdad, con la obligación de descubrir la verdad objetiva". En un sentido similar, Julio Maier en su texto denominado "El Ministerio público ¿un adolescente?" manifestó que este se configura como "órgano de persecución objetivo e imparcial, a semejanza de los jueces, con una tarea presidida por la misma meta, colaborar en la averiguación de la verdad y actuar el derecho penal material".

39 Esta dinámica se produce en la medida que la tarea investigativa se encuentra teñida de una política criminal que se atiene, en buena parte, a criterios inmediatistas que buscan terminar con la delincuencia lo antes posible y con el menor gasto de recursos. Es tal la política de expandir lo punitivo, que si se compara con la región, Chile se encuentra entre las naciones con mayores tasas de encarcelamiento, concretamente en el país se alcanza la cifra de 317 personas por cada 100.000 habitantes (Fuente: Acta de la Comisión de Constitución, Legislación y Justicia. 358 2a Legislatura, sesión $57^{a}$ ordinaria, 21 diciembre 2010). Estas cifras demuestran que en Chile, en las últimas décadas, se ha impuesto una lógica neoliberal que ha propendido al menoscabo del rol social del Estado, al aumento en la severidad de las penas y a la perpetuación de la inequidad social.

40 Bovino, Alberto: "De la verdadera, no hay derecho, Ingeniería de la verdad, procedimiento penal comparado" [en línea] <http://nohuboderecho2.blogspot.com/2008/12/ingeniera-de-laverdad.html>

${ }^{41}$ Maier, Julio: “El Ministerio Público: ¿un adolescente?”. El ministerio público en el proceso penal, Roxin, Klaus y otros. Buenos Aires, Ad Hoc, 2000, p. 35.
} 
Cociña - La dinámica entre la búsqueda de la verdad y las convenciones probatorias...

objetiva, tenderán - en vista de las metas que tienen trazadas y para evitar aumentar su carga laboral- a una investigación más bien incriminatoria. De ahí que la imagen originaria del Ministerio Público como órgano guiado por el principio de objetividad se vuelve borrosa, en tanto en su labor más que determinar la verdad, prima la eficacia.

Los incentivos perversos que se pueden percibir a nivel de la Fiscalía, también se encuentran en la Defensoría Penal Pública, debido a que a este organismo lo aquejan presiones externas, internas, una gran carga de trabajo e indicadores de desempeño que evalúan su labor según parámetros de eficacia. De esta manera, su tarea no se exceptúa de los alicientes perversos. Así, si el defensor puede realizar su trabajo utilizando un menor esfuerzo ¿por qué preferiría un mayor desgaste?

Esta interrogante igualmente es útil planteársela respecto de los demás intervinientes del proceso penal, ya que también a estos los aqueja la excesiva carga de trabajo y las metas de gestión. De ahí que Damaska señala que "las partes pueden hallarse presionadas a llegar a acuerdos en bien de intereses más amplios, incluida la preocupación burocrática por una gestión fluida del caso". ${ }^{42}$

Lo anterior en el caso del juez se traduce en que debe responder a determinados objetivos que le imprime su propia institución, y si bien no se encuentra obligado a ello directamente, sí lo está indirectamente, porque el Poder Judicial constituye una estructura jurídica escalonada que se atiene a ciertos parámetros de funcionamiento y gestión, que muchas veces no van de la mano con la finalidad de averiguación de la verdad. Por lo mismo, Ferrajoli sostiene que la imagen propuesta por Beccaria -en De los delitos y las penas- del juez como indiferente indagador de la verdad resulta esencialmente ingenua.

Por tanto y siguiendo a Taruffo, se descarta que los intervinientes en el proceso cumplan "una función epistémica, fundamentalmente porque las iniciativas y las acciones de las partes no están orientadas hacia la búsqueda y el descubrimiento de la verdad. Por consiguiente un procedimiento con una orientación epistémica debiera estar estructurado a fin de contrarrestar $-\mathrm{O}$ al menos minimizar- la tendencia de las partes a distorsionar la verdad". ${ }^{43}$

Sin embargo, el legislador nacional incorpora al proceso penal las convenciones probatorias sin mayor límite, obviando que acudir a la verdad consensual en lo penal constituye un problema complejo, pues el peligro que trae consigo aceptar lo convenido en el ámbito punitivo se traduce en "abrir la puerta" a que la verdad se establezca en relación con lo acordado y no según lo probado en juicio. Esta transacción en la esfera punitiva implica renunciar en cierto grado a la

\footnotetext{
${ }^{42}$ Damaska: ob. cit. (nota 37), p. 231.

43 Taruffo, Michele. Simplemente la verdad, El juez y la construcción de los hechos, Barcelona, Marcial Pons, p. 193.
} 
determinación de la verdad, en la medida que lo relevante deja de ser el juicio como mecanismo de verificación de las imputaciones, y pasa a ser lo convenido por los intervinientes De este modo, se estaría renunciando a explicar lógicamente en qué consiste la justicia de la respuesta judicial, y al final de cuentas, la coherencia del proceso penal.

\section{Conclusiones}

La convención probatoria se erige como un mecanismo de negociación que tiende a dar viabilidad al nuevo sistema procesal penal, al otorgar una respuesta a la necesidad de instituir herramientas que simplifiquen el proceso. Sin embargo, al incorporar lo consensual dentro del proceso penal, la convención probatoria aleja al juez de la comprobación de la verdad, acercándolo a lo convenido-construido como tal. Lo anterior genera ciertas tensiones, si se tiene en cuenta la necesidad de fundar la sentencia judicial en una decisión que se condiga con lo probado en el juicio.

Probablemente los teóricos del sistema acusatorio nieguen lo anterior, por ejemplo, condicionando lo acreditado vía convención, a la aprobación judicial. No obstante, nuevamente la idea misma de prueba derivada de una convención implica algún grado de renuncia a la verdad cognoscible, y su reemplazo por la verdad como acuerdo intersubjetivo. Ello debido a que cuando la prueba se construye a base de lo que las partes pactan, eso de por sí implica reemplazar el recurso a la constatación empírica de lo que se afirma, por lo que se conviene como verdad.

De este modo, con la incorporación de la convención probatoria en el proceso punitivo los intervinientes concretamente no están constatando algo externo-material, sino construyendo idealmente una verdad, a partir de lo que los sujetos convienen como tal. De esta manera, las convenciones probatorias apartarían al tribunal de la verificación de lo real, aproximándolo a lo concertado, con independencia de si lo pactado se ajusta o no al supuesto que la norma concibió. Ahí descansa el peligro que trae consigo este mecanismo, al posibilitar a que se establezca en el proceso punitivo una decisión alejada de la idea de verdad. Bajo esta lógica, no solamente se estaría excluyendo la prueba como mecanismo de verificación y control, sino también la funcionalidad del juicio oral, que sustenta la respuesta judicial.

En todo caso, lo anterior no es per se negativo, si se considera que la idea de verdad no siempre es perfectamente conciliable con las garantías infranqueables del individuo de cara al ius puniendi. Así, si el sistema penal tuviera como único objetivo indagar la verdad, no existirían límites a su indagación. Situación que se contrapone con lo que ocurre en el ordenamiento nacional, donde la búsqueda de la verdad se encuentra restringida no exclusivamente por razones temporales o de 
Cociña - La dinámica entre la búsqueda de la verdad y las convenciones probatorias...

recursos, sino también por límites sustantivos que el mismo legislador establece, en atención que no está dispuesto a que se alcance la verdad a cualquier costo.

Por lo tanto, en un Estado de Derecho el modelo acusatorio ineludiblemente envuelve algún grado de renuncia a la finalidad de averiguación de la verdad, y la convención probatoria apuntaría en el mismo sentido. Sin embargo, en este caso la interrogante de si la simplificación del proceso es suficiente para contrabalancear la pérdida en términos de justicia de la decisión, se respondería en términos negativos. 
REJ - Revista de Estudios de la Justicia - No 18 - Año 2013

\section{BIBLIOGRAFÍA}

* ACCATINO, Daniela: “Certezas, dudas y propuestas en torno al estándar de la prueba penal" [en línea] http:/ / mmn.scielo.cl/scielo.php?pid=S0718-68512011000200012@script=sci_arttext.

* BOVINO, Alberto: 'De la verdadera, no hay derecho, Ingeniería de la verdad, procedimiento penal comparado" [en línea] http:/ / nohuboderecho2.blogspot.com/2008/12/ingeniera-de-la-verdad.html.

* BOVINO, Alberto y COURTIS Christian: "Por una dogmática conscientemente política" [en línea] bttp:/ / nohuboderecho2.blogspot.com/2008/11/por-una-dogmtica-concientemente-poltica.btml.

* CERDA, Rodrigo: Etapa intermedia, juicio oral y recursos. Librotecnia, Santiago, 2003.

* DAMASKA, Mirjam: Las caras de la justicia y el poder del Estado, análisis comparado del proceso legal. Editorial Jurídica de Chile, Santiago, 2000.

* FERRAJOLI, Luigi: Derecho y Razón: Teoría del garantismo penal. $5^{a}$ ed. Madrid, Trotta, 2001. Derechos y Garantias, La ley del más débil. Trotta, Madrid, 2001.

* FERRER, Jordi: "Derecho a la prueba y racionalidad de las decisiones judiciales", en Jueces para la Democracia (47): 27-34, julio 2003.

La valoración racional de la prueba. Madrid, Marcial Pons, 2007.

Prueba y verdad en el Derecho. Madrid, Marcial Pons, 2005.

"Los estándares de la prueba en el proceso penal español" [en línea] bttp:// www.uv.es/CEFD/15/ferrer.pdf.

* FOUCAULT, Michel: La verdad y las formas jurídicas. Gedisa, Barcelona, 2003.

"Microfisica del poder" [en línea] < currtualffilosofia.cu/almacen/libros/Foucault...Microfisica-delPoder.../file $>$ [consulta: 3 agosto 2011].

- FUSCH, Andrés: Consideraciones teóricas y prácticas sobre la relación entre proceso, prueba y verdad. Editorial Metropolitana, Santiago, 2010.

* GASCÓN Abellán, Marina: “La prueba judicial. Valoración racional y motivación” [en línea] http:// www.uclm.es/postgrado.derecho/_02/web/materiales/filosofia/Prueba.pd.

Los hechos en el derecho. Bases argumentales de la prueba. Madrid, Marcial Pons, 1999.

* GONZÁLEZ, Graciano: "La teoría consensual de la verdad en J. Habermas" [en línea] bttp://fs-morente.filos.ucm.es/docentes/arnaiz/textos/Habermas.pdf.

* GUZMÁN, Nicolás: La verdad en el proceso penal. Una contribución a la epistemología jurídica. Editores del Puerto, Buenos Aires, 2006.

* MAIER, Julio: “El Ministerio Público: ¿un adolescente?”, en El ministerio público en el proceso penal, Roxin, Klaus y otros. Buenos Aires, Ad Hoc, 2000.

* HASSEMER W.: "La verdad y la búsqueda de la verdad en el proceso penal” [en línea] http:/ / www.ucab.edu.ve/tl_files/Derecho/Archivos/Varios/la\%20verdad\%20y\%20la\%20busqueda $\% 20 \mathrm{de} \% 20 \mathrm{la} \% 20 \mathrm{verdad} \% 20$ en $\% 20 \mathrm{el} \% 20$ proceso $\% 20$ penal $\% 20 \% 28$ winfried\%20hassemer $\% 29$.pdf.

* HerZOG, Félix: "La crisis de los principios espirituales y sociales del proceso penal reformado", Revista Ius et Praxis 15, 2009.

* Horvitz, María y LÓPEZ, Julián: Derecho procesal penal chileno. Editorial Jurídica de Chile, Santiago, 2002.

* ORMAZÁBAL, Guillermo: Iura novit curia. La vinculación del juez a la calificación jurídica de la demanda. Ediciones Jurídicas y Sociales, Madrid, 2007.

* PEÑA, Carlos: "Los derechos humanos en el nuevo procedimiento penal" [en línea] http:// mingaonline.uach.cl/pdf/revider/v11/art18.pdf. 32(2009).

"Habermas y el problema de la verdad", en Cuadernos de Filosofía del Derecho, Doxa, 
Cociña - La dinámica entre la búsqueda de la verdad y las convenciones probatorias...

* TARUfFO, Michele: La prueba de los hechos, Milán, Trotta, 2002.

"Narrativas judiciales" [en línea] http://www.scielo.cl/scielo.php?pid=S071809502007000100010 osscript=sci_arttext.

Simplemente la verdad: el juez y la construcción de los hechos. Marcial Pons, Madrid, 2010.

“¿Verdad Negociada?”, Revista de Derecho, 16 (1): 129-151, 2008. 